\title{
Chapter 10 \\ The Australian Context: National, State and School-Level Efforts to Improve Schools in Australia
}

\author{
David Gurr, Daniela Acquaro, and Lawrie Drysdale
}

\begin{abstract}
Australia, like many countries, has a history of colonisation and extensive controlled and humanitarian immigration, with this shifting from an Anglo-Celtic emphasis to include, in succession, an emphasis on migrants from Europe, Asia and Africa. This chapter provides several perspectives on evidence-based school development in this changing context. The first focus is on national school-wide improvement initiatives: IDEAS (Innovative Designs for Enhancing Achievements in Schools), which utilises professional learning communities to improve student outcomes; and PALL (Principals as Literacy Leaders) which provides principals with literacy and leadership knowledge to support teachers to improve student reading performance. The second perspective explores the state level through considering work at the Melbourne Graduate School of Education in terms of evidence-based teacher training through the development of a clinical teaching model, and evidencebased school improvement through the Science of Learning Schools Partnership. The final perspective is at the school level, where the development of two schools in challenging contexts are described: the first a school formed from the closure of three failing schools; the second a school that was at the point of closure when the current principal was appointed to turn-it-around.
\end{abstract}

Keywords School development - School improvement - School effectiveness · Success schools · Principal leadership · School leadership · Initial teacher training · Evidence-based improvement

D. Gurr $(\bowtie) \cdot$ D. Acquaro $\cdot$ L. Drysdale

The University of Melbourne, Melbourne, Australia

e-mail: d.gurr@unimelb.edu.au; d.acquaro@unimelb.edu.au; drysdale@unimelb.edu.au

(C) The Author(s) 2022

R. M. Ylimaki, L. A. Brunderman (eds.), Evidence-Based School Development

in Changing Demographic Contexts, Studies in Educational Leadership 24,

https://doi.org/10.1007/978-3-030-76837-9_10 


\section{Introduction}

Australia, like many countries, has a history of colonisation and extensive controlled and humanitarian immigration, with country prosperity partly tied to continued population growth. The last 70 years has seen migration move from an Anglo-Celtic emphasis to include, in succession, an emphasis on migrants from Europe, Asia and Africa. Historically, since the colonial occupation of Australia, schooling has undergone major periods of change (see Campbell \& Proctor, 2014). Initially, governments were little involved in schools and the provision of schooling was left to church schools (Anglican, Catholic and Protestant) or private schools (small schools owned and run by person or family). The private schools did not survive the domination of the church schools and, in the 1870s, the church schools were faced with competition from government schools as the states and territories that existed then all instituted education acts that provided free and secular education (initially for the primary years in the main). Some private schools went on to become larger independent schools, and whilst church schools were challenged by the arrival of widespread government school provision, they survived. This meant that for the first half of the twentieth Century, school education was a mixture of the dominant government school system which charged no or very low fees and provided a secular education, and the many church and non-church independent schools, with the largest number being parochial Catholic schools, often small and attached to a local parish.

In the 1960s, with the number of religious teachers declining, the cost of providing Catholic school education increased dramatically to the point that these schools sought government support. Whilst governments were reluctant to provide this, a pivotal moment occurred when the Catholic schools threatened to close and the Commonwealth Government came to rescue and provided substantial funding; the funding provided to non-government schools has increased considerably over the years to the point now that an independent school serving a socio-educational community with low advantage can get up to $80 \%$ of its operating costs funded by the government. This was also the stimulus for the Commonwealth Government to exert more influence on schools, with this trend continuing through to current times as is explained further in the next paragraph.

The central Commonwealth Government (also called the federal government), oversees regional governments comprised of six states and two territories, with the federation having formed in 1901 from the six states that existed then. Each of these has a department of education, variously named. Education in Australia is a complex interplay between these different levels of government involving nine education departments, and between government and non-government schools. Whilst the responsibility for the provision of government schooling constitutionally rests with the state and territory governments, increasingly there has been federal government influence especially in terms of significant financial grants to both government and non-government schools, the development of a national curriculum, the creation of a national accountability system through the development of a national assessment 
program in literacy and numeracy and public reporting of these results, and other matters. The federal government provides funding for all schools, but does so in a complicated way, with the bulk of the funding distributed by the state and territory governments. Whilst the state and territory governments provide the main funding for government schools and supplementary funding for non-government schools, much of the income for these governments comes from taxation fees collected and distributed by the federal government (e.g. income tax, and the goods and services tax are only collected by the federal government). This federal funding seems to be one of the major areas of contention in the community with government school champions decrying the lack of funds and the amount going to non-government schools, and non-government school champions arguing it is fair that all tax-payers receive some level of financial support for schooling from the government. Mostly these arguments ignore the full complexity of school funding and the significant role that states and territories have for government school funding.

The governance of schools is also complex. Within the multiple external contexts, imposed or otherwise, local school governance arrangements vary greatly (Anderson, 2006; Gurr et al., 2012). Victorian government schools have had compulsory school councils since 1975 and these include school and parent elected members, and typically also have student and community members (elected or coopted). School councils have a role in school accountability and improvement processes with specific responsibilities for finance, strategic planning, policy development and review and principal selection. Whilst government schools in South Australia and the Australian Capital Territory also have similarly long histories of school councils, Australia's largest state, New South Wales, still does not have compulsory school councils. Catholic schools in Australia have a variety of governance arrangements depending on whether they are parochial (under the authority of the parish priest with or without an advisory school board), systemic (under canonical authority and advisory in nature), or congregational (depending on their legal status there are a variety of delegated responsibilities and authorities). Most independent schools in Australia will have a board or council, and most are incorporated (i.e. companies limited by guarantee), regulated by government acts, and expected to adopt the principles of corporate governance. Parent, teacher and student voice is often non-existent or limited in the Catholic and independent governance arrangements.

In this chapter we provide several perspectives on evidence-based school development in this complex and changing context. The first focus is on national schoolwide improvement initiatives and two programs are described. IDEAS (Innovative Designs for Enhancing Achievements in Schools) is an extensive and on-going school improvement project that has developed a framework for establishing professional learning communities to improve school outcomes (e.g. Crowther et al., 2009; Lewis \& Andrews, 2007). PALL (Principals as Literacy Leaders) is an ongoing research, school improvement and professional learning program focussed on improving literacy in schools through providing principals with literacy and leadership knowledge to support teachers to improve student reading performance (Dempster et al., 2017). The second perspective explores the state level through 
considering work at the Melbourne Graduate School of Education in terms of evidence-based teacher training through the development of a clinical teaching model, and evidence-based school improvement through the Science of Learning Schools Partnership Initiative which utilises a cycle of inquiry approach to develop an important learning focus; in 2019 the focus is on using student voice to inform school improvement (solcnetwork.com/solnos2019). The final perspective is at the school level, where the development of two schools in challenging contexts are described; the first a school formed from the closure of three failing schools (Gurr et al., 2018, 2019; Huerta Villalobos, 2013); the second a school that was at the point of closure when the current principal was appointed to turn-it-around.

\section{National Level School Improvement - The IDEAS and PALL Projects}

Gurr (2019) described two major school improvement initiatives. One was a response from a team of researchers at the University of Southern Queensland, led initially by Crowther, to devise a school-wide improvement program that could be used in any school. The other was a collaboration that was instigated by a principal association with federal government support, and involving three universities and school systems from three Australian states and one territory.

\section{IDEAS (Innovative Designs for Enhancing Achievements in Schools)}

IDEAS is an extensive and on-going school improvement project that has developed a framework for establishing professional learning communities to improve school outcomes (e.g. Crowther et al., 2009; Lewis \& Andrews, 2007). From its beginnings in 1997, it was designed to explore how school-based management could be constructed to ensure it had a positive effect on classrooms (Andrews et al., 2004; Crowther et al., 2012; Crowther et al., 2009; Crowther et al., 2002; Lewis \& Andrews, 2007). In particular, the research was concerned with establishing professional learning communities to improve school outcomes. IDEAS involved three components: a research-based framework for enhancing school outcomes that includes development of strategic foundations, cohesive community, appropriate infrastructure, schoolwide pedagogy, and professional learning; a five-phase schoolbased implementation strategy — initiating, discovering, envisioning, actioning and sustaining (this is a process version of the IDEAS acronym; Crowther et al., 2012); and, parallel leadership in which the principal and teachers engage in mutualism (mutual trust and respect), a sense of shared purpose and an allowance of individual expression. 
IDEAS promoted teacher leadership (these are generally middle leaders who are teachers with a leadership position) and defined the core roles of the principal to include: facilitating the development of a shared vision, creating cultural meaning through identity generation, supporting organisational alignment, distributing power and leadership and developing networks and external alliances. IDEAS is a process that is designed to help schools embark on major schoolwide change to teaching and learning. It works through the parallel leadership of teachers (focus on pedagogical development) and principals (focus on strategic development) combining to activate and integrate culture-building, organisation wide professional learning, and development of schoolwide pedagogy, which leads to school alignment and an enhanced school community capacity to improve school outcomes. IDEAS has been shown to lead to improved school outcomes, often concerned with changes associated with teachers and teaching practice such as increased teacher confidence, self-reflection and review, and the development of a professional learning community (Lewis \& Andrews, 2007). Whilst there was less focus on reporting student outcomes in the early stages of the program and less surety about the impact of IDEAS on students (e.g. Andrews et al., 2004; Lewis, 2006), in more recent years there has been clear evidence for improved student learning and behavioural outcomes (Crowther et al., 2012). More substantial evidence of success of the program, with a focus on the sustainability of success, and more research from those outside the project would be useful to confirm the importance of IDEAS (see Wildy \& Faulkner, 2008, and Gurr \& Drysdale, 2016, for discussion of these points). In terms of understanding successful school leadership, its main contribution is to highlight the importance of principals in direction setting (as meta-strategists), in supporting change and the work of teachers, and promoting a distributed view of leadership through the concept of teacher and parallel leadership to support principal efforts in driving school improvement (Crowther et al., 2009; Lewis \& Andrews, 2007).

\section{Principals as Literacy Leaders (PALL)}

This project formed as a response by a principal association, the Australian Primary Principals Association (APPA), to a federal government call for projects to address educational disadvantage. The APPA saw an opportunity to develop primary principals as literacy leaders, and in 2009 a collaboration was born that involved association with the federal education department and a state education department, three universities (Griffith, Edith Cowan and the Australian Catholic University), and the government, Catholic and independent school jurisdictions from the Northern Territory, Queensland, South Australia and Western Australia. PALL was a professional learning opportunity, a school improvement program and a leadership for learning research project. Dempster et al. (2017) described how the project expanded to three further research projects and programs in all six states and two territories it was a vibrant, impactful learning and research program designed to "provide principals with both the literacy knowledge and leadership support they need to assist 
their teachers to improve reading performance in their schools' (Dempster et al., 2017, p. 150). It was a project that clearly linked leadership with learning and did so in the important area of reading development.

An initial review of relevant literature established a program framework, the leadership for literacy learning blueprint that had five components (shared leadership, professional development participation, enhancing the physical, social and emotional conditions for learning, planning and coordinating the curriculum and teaching across the school, and connecting with parent and community support) surrounding a core that had developing shared moral purpose around improving student learning and performance, disciplined dialogue and a strong evidence base to inform practice (Dempster et al., 2012). Schools participated in a two-year program that included completion of five modules (leadership for learning, learning to read, gathering and using reading achievement data, designing and implementing literacy interventions, and intervention evaluation) and the construction of a literacy improvement plan in the first year, and implementation of the plan in the second year. It was a program that focused on what was called The Big Six: oral language, vocabulary, phonological awareness, letter-sound knowledge, comprehension and fluency. Principals were supported by a literacy achievement advisor (usually a system-based peer mentor), and this role was considered to be very important (the importance of having critical friends to support school improvement is well known: Butler et al., 2011; Huerta Villalobos, 2013; Swaffield, 2004; Swaffield \& MacBeath, 2005).

The program was clearly focused on principals, provided considerable support and opportunities for principals to be literacy leaders, and there was evidence that with support they could become better at doing this (Dempster et al., 2017). Importantly, from the beginning the project adopted an inclusive view of leadership, and the development of teachers in leadership roles, such as literacy leaders, or class teachers that became more widely influential, were features of many of the case study schools (Dempster et al., 2017). Teacher leadership (positional and nonpositional) was seen to be 'central to school-wide action' (Dempster et al., 2017, p. 94).

Dempster et al. (2017, p. 150) reported on findings from six PALL studies and concluded that in terms of impact on student achievement, and despite some methodological difficulties in the studies (such as the relatively short nature of the program and problems in getting principals to complete program evaluations), that 'there is certainly considerable evidence of increases in student achievement in reading - at the individual, class, and school level...' However, as with IDEAS, the core focus of the program was not student outcomes per se, but rather changes in what happened in schools. In the case of PALL, changes in how principals led their schools were demonstrated, with flow-on effects to how other staff worked across curriculum, pedagogy, assessment and reporting. In many cases this led to improved student learning outcomes in a short time, with the project hopeful that as time progresses more substantial and sustainable evidence of learning gain will be shown. In some cases, there was evidence of impact on families, although family engagement was an area identified as needing more development and one that is being explored 
in further studies. As for IDEAS, what is now needed is more substantial evidence of success of the program (especially in relation to student outcomes), with a focus on sustainability of success, and more research from those outside of the project.

\section{State/Regional Level School Improvement - MGSE Teacher Training and School Improvement Initiatives}

This section provides an example of university programs that impact on schools in one state. It reports on two programs from the University of Melbourne in the state of Victoria: a leading initial teacher education program, and a school improvement initiative. Each program utilises an evidence-based approach to improve student outcomes and development.

\section{Melbourne Graduate School of Education's Master of Teaching}

In an effort to advance schools and systems, the federal government introduced National reforms through its Student's First (TEMAG, 2014a April) approach which identified four key areas necessary in the improvement of student outcomes: teacher quality, school autonomy, engaging parents in education and strengthening the curriculum. With recognition that, of school-controlled factors, teachers have the most impact on student learning (e.g. Barber \& Mourshed, 2007; Hattie, 2003), the Teacher Education Ministerial Advisory Group (TEMAG) was established to provide advice on how to improve the quality of teachers through a national reform of initial teacher education programs. The enhancement of teacher education was seen to be central in the federal government's plans to 'lift the quality of and respect for the teaching profession' (TEMAG, 2014a April). The advisory group, comprised of leading education tertiary academics and school leaders, identified divergent practices amongst initial teacher education providers and a need for structural and cultural change to improve and align practice. Six key directions and 38 recommendations were outlined in the Action Now-Classroom Ready Teachers (TEMAG, December 2014b) report, with a call for national accreditation, transparent selection processes, evidence-based program design and delivery, greater integration between schools and higher education providers, and evidence of classroom readiness. The report signalled a wave of change in Australia's initial teacher education and by 2017 all initial teacher education programs at the graduate level were required to become 200 point, two-year equivalent Masters programs, accredited against a set of national standards. This meant that a one-year graduate diploma in teaching was no longer able to be offered as a teaching qualification at the graduate level. Aspiring teachers could select between an undergraduate Bachelor of Teaching or a postgraduate 
pathway through the Master of Teaching. Improving the quality of teaching by greater regulation of initial teacher education programs was seen to be fundamental in improving the profession, schools and education outcomes (TEMAG, 2014b December).

The Melbourne Graduate School of Education's (MGSE) Master of Teaching Program was first developed in 2008 when the University of Melbourne moved to the Melbourne Model which emphasised broad areas of undergraduate education, with professional specialisation occurring at the graduate level. As part of this, the then Faculty of Education stopped its undergraduate initial teacher education program and shifted entirely to become a graduate school, with a two-year Master of Teaching program. The design of the program drew heavily from the Stanford Teacher Education Programme (STEP) from Stanford University in California and from the University of Virginia and Bank Street Teachers' College, New York (Kameniar et al., 2017) which adopt an evidence-based clinical approach. The Master of Teaching was the first of its kind in Australia and a paradigm shift in initial teacher education, promising to deliver not only high-quality initial teacher education but also equipping teacher graduates with knowledge in areas such as wellbeing, curriculum or leadership through a carefully constructed Masters level elective offering.

The creation of the Master of Teaching at MGSE pre-dated the TEMAG recommendations, and its success was an influence on TEMAG's recommendation that all graduate initial teacher education courses become two-year Masters programs. The program is evidence-based and designed around a clinical teaching framework (Burn \& Mutton, 2013; Conroy et al., 2013; McLean Davies et al., 2013; DarlingHammond \& Bransford, 2005), the focus of which is to develop teachers who are interventionist practitioners able to assess, diagnose and support the individual learning needs of all students, as well as work with students with mixed abilities. The program teaches its pre-service teachers how to utilise evidence and data about learners to target their teaching in order to improve student learning and development (Dinham, 2013). A central tenet of the clinical model is the centrality of the clients (Alter \& Coggshall, 2009), interdependency of theory and practice and the importance placed on clinical practice in the school context, whereby pre-service teachers are supported to develop their ability to make evidence informed judgements (Kriewaldt et al., 2017). Three core components characterised teaching as a clinical practice profession: (1) a focus on student learning and development; (2) evidence-informed practice; and (3) processes of reasoning that lead to decisionmaking (Kriewaldt et al., 2017). The six tenets underpinning these three components are (Kriewaldt et al., 2017, pp. 154-155):

- The student and their learning needs are pivotal to all decision-making about what, when and how to teach;

- The teacher uses evidence about the student, what they already know and what they are ready to learn to make decisions about subsequent teaching;

- The teacher draws on current research evidence about effective practice in making decisions about how to work with a student or group of students;

- The teacher integrates knowledge about who the student is, including knowledge of their characteristics, circumstances and prior experiences, into decision-making about the student and their own teaching; 
- The teacher evaluates their own impact on student learning on a regular basis; and The teacher exercises professional judgement involving all these elements.

- The teacher exercises professional judgement involving all these elements.

Through a clinical model, the effectiveness of the teaching and learning cycle is heightened as pre-service teachers are explicitly taught the skills necessary to meet the individual needs of students through a process of reasoning and decision making. Pre-service teachers are taught to integrate various forms of evidence about what the student knows or can do, in order to develop their pedagogical thinking (Sahlberg, 2012). The focus of their training is 'on the importance of data, evidence and research in order to determine the next stage or step to advance student's learning' (Kriewaldt et al., 2017, p. 157). A key component of the program has been the development of an assessment and curriculum innovation- the Clinical Praxis Exam (CPE). The task first piloted in 2010, was designed to integrate learning amongst academic subjects and the professional practice component of the program by assessing student's clinical reasoning. 'The CPE is an oral assessment task that involves a cyclical process of analysis and reflection, integrating theory, evidence, practice and evaluation' (Kameniar et al., 2017, p. 58). Research (Kameniar et al., 2017) into the impact of the CPE suggest that students considered it to be the most valuable learning in their studies. Students felt that the task helped them bridge the gap between theory and practice and assisted them in developing greater understanding of 'the complex intellectual, diagnostic, planning, intervention, and evaluative aspects of teaching practice' (Kameniar et al., 2017, p. 62).

The size and scope of the Master of Teaching program expanded with five courses offered in 2019 including secondary, primary, primary and early childhood, early childhood and a secondary internship program which combines study and paid work in a teaching role. Compared to other universities, it was ranked number one for student satisfaction, skills attained in the degree, and $90.7 \%$ of graduates were successful in attaining full time employment, which again was well above the national average of $83.8 \%$ (QILT, 2018). A small scale study completed by the Australian Council for Educational Research (ACER) in 2010 found that $90 \%$ of MGSE Master of Teaching graduates claimed that they were 'well' of 'very well prepared' and they claimed that they had entered the profession with knowledge of best practice, emphasis on deep reflection and reflective practice and an ability to integrate theory and practice in an evidence-based approach (Scott et al., 2010, p. 4).

'While the impact of university programmes on teachers has proved difficult to measure' (Kameniar et al., 2017, p. 54) to date, as part of the National reforms introduced, all initial teacher education providers will be required to submit evidence of student learning impact of programs to their state level accreditation body within 5 years of their initial program accreditation. For most providers, the next couple of years will serve to generate data to better understand what works and why and by 2022, we should begin to see impact data on the effectiveness of Australian teaching programs since the introduction of the recent National reforms. As one of the first programs to be accredited, MGSE's Master of Teaching will be amongst the first to complete Stage 2 of the accreditation process and will utilise teaching performance assessments, graduate outcomes data, graduate and school principal 
survey data and case studies to evaluate graduate and program performance. This data will be useful in confirming the importance of the program in preparing the next generation of teachers.

\section{Science of Learning Partnership Schools Initiative}

Motivated by a desire to improve learning outcomes in Australian schools and funded as an Australian Research Council Special Research Initiative, The Science of Learning Research Centre (SLRC) was established in 2012 by Professor John Hattie at MGSE.

As part of the work of the SLRC, a Science of Learning Partnership Schools Initiative (SLPSI) was created in 2017, offering schools an opportunity to improve learning outcomes in their schools. The initiative teaches school leaders and educators to implement an evidence-based cycle of inquiry to identify school needs, use high impact teaching and learning interventions and evaluate the effectiveness of the interventions. Through the program, schools work with leading education researchers over the course of 1 year. The partnership requires the commitment of the school principal to engage in the program which includes intensive professional development programs, forums, school professional development sessions and ongoing personalised support to achieve school improvement goals. The school is taught to use evidencebased approaches to improve student educational and wellbeing outcomes. In order to do this, the principal and teachers must establish a deep understanding of how to diagnose the school's needs, implement evidence-based interventions, and evaluate their impact. The fundamental goal of the program is to connect research with practice for the purpose of translation and impact on student outcomes. In its first 2 years, the program allowed schools to focus on an area of inquiry unique to their school, whereas the program in 2019 has trialed a new approach delineating a focus on Using Student Voice to Drive Improvement which is described at (https://solcnetwork.com/solnos2019/). The program has four main stages:

Stage 1: Diagnose- Pre-test diagnostic tools utlilising student voice are used to identify areas for improvement within the school.

Stage 2: Intervention- Professional learning and online modules are provided to support teacher improvement using evidence-based interventions.

Stage 3: Implementation: Leadership coaching supports school leaders to understand the science of effective implementation.

Stage 4: Evaluation: Post-intervention measures are provided to support teachers and school leader to evaluate impact and plan for next steps.

Within the program, schools are offered a series of intensive professional development programs at the University of Melbourne for several members of their staff delivered by MGSE academics. In addition, staff participate in several forums, including participating in online learning activities. Whole school professional learning is also offered to all school staff with ongoing personalised support and access to a suite 
of online professional learning resources. The program, albeit still in its infancy, has attracted strong numbers with 16 schools enrolled in the 2019 program. The rationale for the initiative derives from Hattie's (2015) work on collaborative expertise where he sees the importance of school leaders coming together to work and learn from one another. The premise of the SLPSI is to create a culture of collaborative expertise in which 'highly expert, inspired and passionate teachers and school leaders working together to maximize the effect of their teaching on all students in their care' (Hattie, 2015: p. 2). Hattie $(2012$, 2015) encourages school leaders and staff to focus on measuring impact on student learning; work together to evaluate their impact; to move from what students know to explicit success criteria; to build trust and welcome errors and opportunities to learn; to attain maximum feedback from others about their effect; understand the difference between surface and deep learning; and knowing when to and how to challenge students. Anecdotal evidence suggests that the program of learning has made an impact on participating schools, however the program in 2019 will commence a more formal stage of evaluation. Whilst internal satisfaction data rate the program highly with testimonials from participants outlining the impact on their development as educators and on their school more broadly, more substantial evidence of the effectiveness of the initiative is needed to know how this program of learning is making a sustained impact on student and school outcomes.

\section{School Level Improvement: Evidence-Based Improvement in Two Schools}

Schools in all educational systems in Australia are moving to evidence-based school development. This section of the chapter provides an example of two government schools in challenging circumstances that have developed their own individual school improvement strategy based on several sources including evidence-based research, school data and effective decision-making processes.

\section{Hume Central Secondary College}

Hume Central Secondary College is a school we have previously written about as part of our contribution to the International Successful School Principalship Project and International School Leadership Development Network (Gurr \& Drysdale, 2018, 2019; Gurr et al., 2018, 2019; Huerta Villalobos, 2013; McCrohan, 2021). This school demonstrates how a school at the local level can autonomously construct its own evidence-based improvement goals and strategies using several sources to improve student outcomes. Drysdale and Gurr were involved with the principal for many years and with the school at various levels. For example, Drysdale was a critical friend, professional development facilitator in the school's 'emerging 
leaders' program', a participant observer in regular leadership meetings, and member of the research team that investigated the school. The major formal research methodologies used have been that of in-depth, multiple perspective case studies based on ISSPP protocols: Huerta Villalobos (2013) conducted masters level research about the role of critical friends at the school and McCrohan explored the leadership of the principal (Gurr et al., 2018, 2019; McCrohan, 2021). This provided a unique and valuable in-depth insight into the school's strategies, practices and leadership. The studies took place between 2009 and 2016.

Hume Central Secondary College was established as a new school in 2009 because of a government school improvement project in the Northern Region of Melbourne. The project was aimed at transforming the educational opportunities and achievement levels of students in one of the most disadvantaged communities in Australia. The school was born out of the ashes of three failing schools that were closed and reopened as one school occupying three new campus sites - two Year 7 to 9 campuses and one Year 10 to 12 campus. The school appointed Glenn Proctor as an executive principal overseeing the three campuses. Whilst each campus site had its own campus principal, our research findings demonstrated that Glenn was the driving force for change through setting-up the early initiatives and interventions.

What was interesting in this case study was that while the government system central and regional education administrations offered programs and professional development opportunities for the school, Glenn Proctor was confident that the school could forge its own pathway to success by exploring multiple sources of authoritative expertise and research-based studies to establish its own direction and develop its own targets and strategy. At the same time, Glenn was responsible for initiating a rigorous process for collecting and analysing school and student data.

Glenn and his team developed an integrated plan for change. The strategy was to set a new vision for the school; establish targets for students and staff; develop strategies to improve teaching and learning; build leadership and staff capacity; improve student behaviour, attendance and achievement levels; develop a new viable and relevant curriculum that engaged students; and develop a new school culture. Each strategy was evidence-based. The strategy was largely based on the four practices of successful leaders championed by Leithwood and colleagues (e.g. Leithwood \& Riehl, 2005; Leithwood et al., 2010): setting direction, developing people, redesigning the organisation, and focusing on student learning. Following is our analysis of the school focussing on building leadership capacity, redesigning the organisation, building teacher capacity to improve teaching, support from external experts and agencies and establishing a performance and development culture.

\section{Building Leadership Capacity}

Glenn focused on developing the capacity of the campus administrators and the 16 leading teachers from the three campuses. The school invested in several leadership programs and opened opportunities for professional learning. Two of the programs conducted by a local Technical and Further Education institute (TAFE) - Coaching 
for Success' and 'Coaching for Improvement' - were highly intensive workshop programs conducted over several days. These formed the basis for ongoing leadership training for the next 6 years.

The focus of leadership team meetings was professional learning. Activities included professional reading, presentations by leadership team members, guest speakers, data analysis and review, strategic planning, and setting targets for improvement. Key topics for team meetings included managing change, team building, instructional leadership, instructional models of learning, peer coaching and review, professional conversations, and differentiation of lessons according to student needs.

Glenn regularly set professional reading for the school leaders. Each year Glenn distributed and set a leadership book that included: Our Iceberg Is Melting (Kotter \& Rathgeber, 2006); Leadership on the Line (Heifetz \& Linsky, 2002); The Practice of Adaptive Leadership (Heifetz et al., 2009); and Leading School Turnaround (Leithwood et al., 2010). Chapters, topics and ideas were discussed during leadership team meetings.

The professional learning was aimed at changing leader behaviour which was seen by Glenn to be central to organisational change and improvement. The emphasis on leadership development was re-enforced in the opening of the School Review Report (2009: 3) conducted in the first year of the school:

"(T)he emphasis has been rightly on building leadership capacity to drive overall change. This has been progressed through a focus on changing leadership behaviours using a range of targeted and sophisticated strategies and provides an excellent foundation for the major challenge of improving student outcomes through quality teaching and learning."

Glenn placed high expectations on leaders. Whilst there was significant support for leaders, those who did not meet expectations were replaced. This was reflected the school policy, Leading Teacher Renewal of Tenure Policy, which outlined the expectations of the leadership roles and criteria for application and appointment. Every 2 years all leadership positions were opened for renewal. In the 2013 round of appointments, one third of the 16 positions were awarded to teachers external to the school. Glenn believed that getting the right people in place was critical and more effective than training the wrong people and he stated, 'If you want an excellent leadership team you must have excellent people.'

To support leadership development, the school conducted an emerging leaders' program for teachers and staff who aspired to more senior leadership positions. This was conducted by Lawrie Drysdale for $1.5 \mathrm{~h}$, eight times a year.

\section{Redesigning the Organisation}

Glenn introduced a distributive leadership structure based on the work of Harris (2009). Glenn believed that to secure the best from teachers and staff, they had to be 'empowered' and the distributed leadership model was best able to support this. In 2012 Glenn created 98 leadership positions (positions with responsibility) for 120 teaching staff $80 \%$ of teachers had leadership responsibilities compared with $30 \%$ previously. 
Another example of using research to restructure the school, Glenn used a paper called Schools that achieve extraordinary success: How some disadvantaged Victorian schools 'punch over their weight' (Zbar et al., 2009). This paper outlined the findings of research on Victorian schools in challenging circumstances that achieved beyond expectations. The paper noted four pre-conditions - strong leadership that is shared, high levels of expectations and teacher efficacy, ensuring an orderly learning environment as a precondition, and a focus on what matters. The school used this as a reference and basis for its improvement strategy.

Team orientation was an important aspect. Glenn established common team meeting procedures and protocols. There was a focus on team development and collaborative decision making within teams. Team leaders across the disciplines and numerous functions met regularly to discuss common issues and challenges. External experts supported team development.

\section{Building Teacher Capacity to Improve Teaching}

To improve teaching and learning, Glenn sought to focus on professional practice and purposeful teaching. A key strategy was to develop a common instructional model of teaching. Glenn and the leadership team investigated the research of John Hattie (2009) and adopted his approach by developing what was entitled 'The Hume Central SC Explicit Instructional Model'. This became the default model of teaching in the school and staff were trained in how it operated.

Establishing an orderly learning environment was a high priority in the first year of operation. The student management policy was ineffective, student behaviour was extremely poor, absences were high and engagement very low. Glenn set about developing a common approach to student management by adopting a student management program offered by the regional office and based on the work of Ramon Lewis (2008). The program proved to be important in reducing student absence and promoting engagement.

Another key initiative to improve student engagement was to change the curriculum and its delivery. Glenn initiated Curriculum Design Teams that brought discipline teams of teachers together from the three campuses to develop the curriculum to better meet student needs by building teacher capacity for differentiating teaching and achieve the aim of 2 years of learning in 1. Common assessment tasks were also set so that teachers had a common understanding of standards and satisfactory completion and were consistent in their assessment of student progress.

Another key strategy for improving teaching and learning was to focus on classroom practice. A process for monitoring and improving teacher professional practice was established that required teachers to reflect on their practice and plan for improvement. To support this approach the annual review system was evaluated and enhanced; teachers were encouraged to participate in peer observation of classroom practice; and a coaching culture was established starting with literacy and numeracy coaches and then introducing triads of teachers who would take turns to observe 
each other in the classroom. The triad coaching process was modelled by all members of the leadership team before it was introduced throughout the school.

\section{Support from External Experts and Agencies}

Glenn was also highly successful in drawing on external agencies for support. These played a significant role in positively influencing the school's performance. Welfare agencies, partnerships with other schools in other education systems (independent schools), and programs and facilities from the local TAFE institute were examples.

A key influence on improvement was engaging two critical friends who were expert in leadership and school improvement. The two critical friends were instrumental in guiding and supporting the improvement strategy and supporting the leadership team (Huerta Villalobos, 2013). Educational consultant Vic Zbar was engaged to work with the leadership team to implement a framework of school improvement based on his research in successful schools in disadvantaged areas (Zbar, 2013). Vic also guided an extensive school review and supported the capacity building of leadership team. As noted previously, Lawrie Drysdale, was engaged (voluntary) as a critical friend from 2009 to 2015 . He regularly attended senior leadership meetings and conducted a program for emerging leaders for 6 years. Huerta Villalobos (2013) found that the critical friends had a direct impact on the work of senior and middle level leaders, and through this, an indirect impact on the work of teachers and student outcomes. They were not only able to provide professional support, advice, reflection, but also showed a willingness to question and challenge.

\section{Establishing a Performance and Development Culture}

Finally, the strategy to establish a performance and development culture in the school was based on setting high expectations and new benchmarks. Glenn set high expectations of students, teachers and the community; however, he recognised that culture building takes time. He constantly questioned the behaviour, norms, beliefs, attitudes and assumptions of teachers. Glenn acknowledged that changing low expectations into high expectations was an ongoing education for the whole school community. But he was resolute to succeed. As one campus principal said, 'He does not take his foot off the pedal.'

\section{School Performance}

After 6 years there emerged evidence that Glenn's strategy was successful. Whilst student achievement was still a work in progress, other targets were highly successful. Evidence from survey and recorded data show that engagement, student 
wellbeing and attendance had improved. For example, within 5 years, student attendance increased from $60 \%$ to $90 \%$; entry to tertiary education went from $80 \%$ to 97\%; student and parent attitudes to school improved to be above state medians; enrollments increased against the trend in other local schools; and there were good signs of improved student learning with results on the national literacy and numeracy testing program at the level of similar schools. Whilst final year results remained low between 2010 and 2017, in 2018 these results improved significantly to be just below the state average for government schools.

With this improvement, the school is better able to meet community expectations for quality school. Families that would have once upon a time driven past the school are now enrolling their children. It appears that the challenge is not in turning the school around but sustaining the change and continuing to improve.

\section{Scoresby Secondary College}

Scoresby College is another example of a school in challenging circumstances that under the leadership of a new principal used evidence-based methodology to drive school improvement. As with the previous case, Drysdale and Gurr have a long association with the principal, and the research evidence is from a multiple perspective case study conducted by McCrohan (2021) based on the ISSPP research protocol and supported by Drysdale and Gurr. Drysdale was a challenge partner in the school's review conducted in 2018.

The school was established in 1975 and is a Year 7-12 coeducational government school situated in the south eastern suburbs of Melbourne, approximately 40 kilometres from the Melbourne CBD. In 2018 the enrollment was 253 students. There were 30 staff and 10 non-teaching staff. Gail Major was appointed as an executive principal with the challenge to save the school from closure (Major, 2018). When she took over in 2015 the school's results were declining, its reputation poor, and it was perceived to have a dysfunctional culture and poor student management. The school, led by Gail, is an example of a school that has developed its own improvement strategy using evidence from several sources. Following is our analysis of the school's improvement strategy: setting new direction, teaching and learning, leadership for professional capacity building, and focus on student needs.

\section{School Improvement Strategy}

From our research it was clear that Gail had carefully diagnosed the situation and developed a plan based on her observation and findings. Like Hume Central, the plan reflected the four practices of Leithwood and Riehl (2005). Gail set about establishing a new direction, transforming teaching and learning, building staff leadership and professional capacity, re-organising the school, developing a positive high expectations culture, and focusing on student learning. Gail's and the school's 
journey were clearly identified in school documents and case study research. The School Self-evaluation Report 2018 (Scoresby Secondary College, 2018a) shows the school's key strategies from 2015 to 2018. Gail also documented every initiative and activity completed by the school from 2014 to the present (Scoresby Secondary College, 2018b). The following points do not include all the evidence-based approaches but provides a valuable insight to the improvement strategy.

\section{Setting New Direction}

After strong community consultation, a clear vision and values statement for the College was developed. The new vision identified what the college stood for, the beliefs and guiding principles that underpinned everything that the school community did, and it articulated the quality of education that was expected. In 2015, the college launched its vision to become the College of Choice. The values of integrity, nurture, success, pride, innovation, respect and excellence were expressively outlined in detail. This was supported by creating a new school brand, new uniform, and the establishment of a safe and orderly environment. The new motto was inspiring brilliance.

\section{Teaching and Learning}

Curriculum and pedagogy were reformed through five major strategies:

1. Gail developed an instructional core. She was influenced by City et al. (2009) who outlined three key ways to improve student learning at scale: raise the level of content that students are taught; increase the skills and knowledge teachers bring to teaching that content; and increase the level of students' active learning (engagement) of the content.

2. A guaranteed and viable curriculum was developed as this is the most important factor in Marzano's (2003) view of what works in schools. In 2015, she introduced teaching practices to support this initiative. Each student was now guaranteed to be taught in the time available what was imperative to teach, irrespective of the class they were in.

3. An evidence-based instructional framework, known as the Scoresby Instructional Model, was developed and agreed to by all staff. The framework was developed to ensure the adoption of a consistent approach to building teacher practice from Year 7 to 12 . The model was fully implemented in 2017 requiring teachers to deliver all the components of the instructional model and have a goal in their performance and development plan related to peer observation and feedback.

4. The school introduced a 'blended learning' model of instruction. Teachers in each lesson were required to identify learning intentions. Each class lesson was required to rotate three pedagogical components - direct instruction, group work 
and individual activities on their laptops. Gail had introduced this model successfully in her previous school and had presented the model at various conferences and network meetings. The school imbedded the model during 2018.

5. Structural changes were made to support these initiatives. For example, teachers were reallocated to faculty-based areas to support professional dialogue, curriculum teams were created with renewed accountability, and teachers were expected to share their practice. Gail appointed a head of curriculum and pedagogy and teaching and learning leaders. Improvement teams were established that met weekly. The college prioritised collaboration. Teachers were expected to work together to plan learning programs. Team meeting times were timetabled into the program.

\section{Leadership and Professional Capacity Building}

One of the first strategies she embarked on was to establish a strategic leadership team with a clear purpose, moving away from operational to strategic leadership, so all decisions and resourcing (human, physical and financial) were consistent with meeting teaching and learning goals. In 2017 an emerging leaders' program was introduced. An external coach was engaged for emerging leaders to take on authentic leadership through the school review and to actively be engaged in directions for the new strategic plan for the next 4 years (2019-2023).

Initiatives such as a shared leadership model, professional learning communities and growth coaching for performance and development processes, demonstrated programs designed to build capacity. Meeting schedules were designed to provide the opportunity for teachers to develop extensive professional learning plans and professional learning teams that work on a common unit planner and build in collaborative practices. In addition to scheduled meetings times, the college created purposeful learning spaces. The college addressed a major curriculum imbalance by enabling teachers to teach in their own areas of expertise with skills and knowledge to raise achievement.

The college established collaborative partnership with networks, tertiary providers and educational consultants. Sustained professional learning, including peer observation, observations in high performing schools, professional readings, data literacy training for members of the numeracy, and staff exposure to quality presentations and visits by experts were all identified as enablers for improvement.

\section{Focus on Student Needs}

The focus on student needs was central to the school's strategy. Goals were established to develop strong relations between student and teachers, student voice and student leadership. Personalised learning was introduced as a school wide approach to target the needs of each student and monitor performance. The school invited 
Professor Brian Caldwell (Former Dean of Education, The University of Melbourne) to provide a workshop on the indicators of personalised learning (Scoresby Secondary College, 2018b). The school adopted this approach. Using this model teachers were able to know the progress of each student on a continuing basis and were able to deliver appropriate teaching methods to maximise the skill set of each student.

Student voice was a major focus and was promoted to a core group of students although the avenue to develop this with all students was not clear. Students were encouraged to provide feedback to teachers on learning and teaching materials with the aim to give student greater voice in how they learn rather than what they learn.

\section{Findings}

As part of the school review conducted in 2018, the school identified four major achievements from 2015 to 2018 (Scoresby Secondary College, 2018a): college partnerships; raising achievement; student leadership; and respectful relationships education in schools. These were verified by the external reviewers who identified that the school now had a visible positive learning climate, pride demonstrated by students and staff, high expectations, student voice and advocacy, and effective professional collaboration. Student, staff attitudes, and parent opinion had increased to be above state averages. Most significantly was the student growth in final year results and on year 7 and 9 results on the national literacy and numeracy testing program. Results were either at or above that of schools with similar levels of educational advantage.

Scoresby Secondary College is an example of a school that has been transformed over the past 3 years with a high performing culture, improved curriculum and many new staff. Student achievement has been publicly recognised. Melbourne's largest circulation newspaper, the Herald Sun newspaper, published an article regarding the great improvement that has occurred at Scoresby Secondary College (Argoon, 2018). It noted that in 2015 the school data showed that the school was declining in the national literacy and numeracy testing program for years 7 and 9 . The article confirmed our own analysis that the school showed the characteristics of a turnaround school and was recognised as one of the most improved schools for final year results in the state. Results on the national literacy and numeracy testing program confirmed the improvement and valued added for students in Year 9. Scoresby Secondary College is an example of a school that has been transformed over the past 3 years with a high performing culture, curriculum and many new staff. Student achievement has been publicly recognised, and the school has successfully demonstrated the link between evidence-based methodology and positive school performance. 


\section{Discussion}

The programs described are symptomatic of an educational climate focussed on school choice, quality and equity (the following arguments are taken from (Gurr, 2020). Major issues that are at play in Australia include federal versus state/territory government control of education, disputes about the amount of school funding going to government, Catholic and independent schools, increased emphasis on parental choice, the influence of student testing programs, and school equity and quality concerns. The core role of federal and state/territory governments has not changed substantially since the turn of the century (and indeed, over the previous century). However, as was mentioned previously, the trend since the 1960s of a greater federal role has continued through aspects such as increased federal school funding to both government and non-government schools, the introduction of national curriculum, increased testing and accountability, substantial grants programs for building and digital infrastructure, and the importance of international testing programs for policy and practice changes.

Funding issues and parental choice are major sources of angst as the right to school choice is somewhat limited by the funds parents have to spend on schools, and despite all schools getting some government funding (ranging from approximately $90 \%$ for a government school to $10 \%$ for a high-fee independent school), family school costs range from a few hundred dollars (government schools) to over $\$ 35,000$ (high-fee independent schools), which is nearly half of the average Australian wage. There is now a quasi-market for schools that has created 'an uneven playing field that benefits a portion of the community more than it does the remainder' (Bonner \& Shepherd, 2016, p. 7), and the neo-liberal stance of successive federal and state governments, whilst valuing parental choice, has had the unintended consequence of enhancing inequity. However, these issues combined with a focus on school performance caused by concerns about performance on national and international testing programs (Bentley, 2018; Hattie, 2016), have, fortunately, resulted in a focus on equity and quality. Whilst there are justifiable concerns about the intended and unintended consequences of national and international tests (see the papers in the special issue of Educational Philosophy and Theory, 47(2), 2015, for several critical perspectives on national testing and reporting in Australia), these tests have highlighted performance concerns related to overall performance and disparity in performance, and once these are exposed there is an imperative, taken up by governments, to address them.

It is this focus on equity and quality that has driven all of the six programs we have described - from the nationally focussed and research-driven IDEAS (school improvement) and PALL (instructional leadership) projects, through to state/ regional initiatives to improve initial teacher education and to help schools create data-driven improvement, to the two examples of schools in challenging contexts that have used knowledge and data to improve student and school outcomes. These programs also align with Caldwell's call for greater structural and professional autonomy to enable schools to be in control of what they do (Caldwell, 2016, 2018). 
Caldwell (2016) argued that school autonomy seems to have a premium or advantage for those systems that can provide this, provided that schools have the capacity to utilise this autonomy and that professional forms of accountability are in place to guide judgement on what to do. Caldwell made a distinction between structural autonomy through policies, regulations and procedures, and professional autonomy in which teachers have the "capacity to make decisions that are likely to make a difference to outcomes for students, and this capacity is exercised in a significant, systemic and sustained fashion' (Caldwell, 2016, p. 4). For school autonomy to make a difference to students, professional autonomy is required, and there needs to be alignment between the various systems that surround schools (such as the state/ territory/federal layers of government in Australia) (Caldwell, 2018).

At the state/regional level, two programs from a leading university were described, but the evidence of their impact was weak relying mostly on anecdotal perceptions of worth, with some evidence of attitudinal change, but no trustworthy evidence as yet of impact on students. At the school level, however, the two described schools both had improvement agendas that utilised trustworthy evidence sources, and both were able to demonstrate significant changes in structure, processes, leadership development, and teaching and learning, that ultimately was impacting on student learning. What seems to be evident with the two schools was that they had: a clear sense of what was needed; evidence to support their changes; mandates and will to stay true to the improvement course; control over key variables; a focus on developing the capabilities in staff to implement the changes; use of data to inform school and classroom changes; and a concern to produce evidence to show success. The other programs have some of these elements, but not all, and their true success can only be measured through the improved outcomes of schools and students.

Amidst international testing and benchmarking, schools have been placed under extreme scrutiny to offer more, and to guarantee improved student outcomes. It is school leaders who are facing the brunt of criticism around declining literacy and numeracy and their impact in student success is being scrutinised more than ever before (Bentley, 2018; Bonner \& Shepherd, 2016; Hattie, 2016; Savage, 2017). Timperley (2010) advocates that school leaders need to have sufficient understanding of evidence informed practice in order to evaluate their own effectiveness and support teachers in their work. She goes on to suggest that "when teachers are provided with opportunities to use and interpret a range of evidence in order to become more responsive to their students' learning needs, the impact is substantial" (Timperley, 2010:10). Whilst each school has differing needs and operates within a distinct context, it is widely understood that a common approach to teaching and learning can have a positive impact on student outcomes and an important role for school leaders is to ensure quality and consistency of practice. Leaders with high expectations for learning and an understanding of their role in leading teaching and learning can improve student outcomes, and the two case schools described in this chapter highlight examples of how this happens. Our Victorian school examples support Caldwell's $(2016,2018)$ call for greater structural and professional autonomy to promote school success, and suggest that a shift towards school autonomy can provide an impetus for schools at the local level to set their own improvement 
pathway and introduce processes to measure, not only key elements that contribute to school success, but those that will guarantee student achievement. Importantly, we have shown elsewhere (Gurr \& Drysdale, 2019), how schools in Victoria are supported by central and regional system leadership, and how this system leadership, combined with schools with a high degree of autonomy, can lead to exceptional school and student performance.

When we began this chapter, we intended to describe evidence-based practice at the national, state and school level through examples of programs and practice. What is noticeable across each of the examples is a commitment to education and a fundamental desire to improve schools and student outcomes. Whilst the programs are quite distinct, each focuses on best practice utilising an evidence base to underpin the various approaches to improve teaching and learning. The continued implementation of evidence-based programs like these, inevitably makes an impact on the quality of teaching and learning in Australian schools, and may, in time, even impact on international test performance.

\section{References}

Alter, J., \& Coggshall, J. (2009). Teaching as a clinical practice profession: Implications for teacher preparation and state policy. National Comprehensive Center for Teacher Quality.

Anderson, M. (2006). Being a school councillor in a government secondary college in Victoria: Constructions of role and meaning. Doctor of Education thesis, The University of Melbourne.

Andrews, D., Conway, J., Dawson, M., Lewis, M., McMaster, J., Morgan, A., \& Starr, H. (2004). School revitalisation the IDEAS way (Monograph, 34). Australian Council for Educational Leaders.

Argoon, A (2018). Students put the score into Scoresby, Herald Sun Newspaper 20 November.

Barber, M., \& Mourshed, M. (2007). How the world's best performing school systems come out on top. McKinsey \& Company.

Bentley, T. (2018). The responsibility to lead: Education at a global crossroads (Monograph, 57). Australian Council for Educational Leaders.

Bonner, C., \& Shepherd, B. (2016). Uneven playing field: The state of Australia's schools. Centre for Policy Development.

Burn, K., \& Mutton, T. (2013). Review of research informed clinical practice in initial teacher education. British Education Research Association and RSA Action and Research Centre.

Butler, H., Krelle, A., Seal, I., Trafford, L., Drew, S., Hargreaves, J., Walter, R., \& Bond, L. (2011). The critical friend: Facilitating positive change in school communities. ACER Press.

Caldwell, B. J. (2016). The autonomy premium: Professional autonomy and student achievement in the 21st century. ACER Press.

Caldwell, B. J. (2018). The alignment premium: Benchmarking Australia's student achievement, professional autonomy and system adaptivity. ACER Press.

Campbell, C., \& Proctor, H. (2014). A history of Australian schooling. Allen \& Unwin.

City, E. A., Elmore, R. F., Fiarman, S. E., \& Teitel, L. (2009). Instructional rounds in education: A network approach to improving teaching and learning. Harvard Education Press.

Conroy, J., Hulme, M., \& Menter, I. (2013). Developing a 'clinical' model for teacher education. Journal of Education for Teaching: International Research and Pedagogy, 39(5), 557-573.

Crowther, F., Andrews, D., Morgan, A., \& O'Neill, S. (2012). Hitting the Bullseye of school improvement: The IDEAS project at work in a successful system. Leading and Managing, $18(2), 1-33$. 
Crowther, F., Ferguson, M., \& Hann, L. (2009). Developing teacher leaders (2nd ed.). Corwin Press.

Crowther, F., Kaagan, S., Ferguson, M., \& Hann, L. (2002). Developing teacher leaders. Corwin Press.

Darling-Hammond, L., \& Bransford, J. (Eds.). (2005). Preparing teachers for a changing world: What teachers should learn and be able to do. Jossey Boss.

Dempster, N., Konza, D., Robson, G., Gaffney, M., Lock, G., \& McKennariey, K. (2012). Principals as literacy leaders: Confident, credible and connected. Australian Primary Prinicpals Association.

Dempster, N., Townsend, T., Johnson, G., Bayetto, A., Lovett, S., \& Stevens, E. (2017). Leadership and literacy: Principals, partnerships and pathways to improvement. Springer.

Dinham, S. (2013). Connecting clinical teaching practice with instructional leadership. Australian Journal of Education, 57(3), 225-236.

Gurr, D. (2019). Australian considerations in relation to instructional leadership and leadership for learning. In T. Townsend (Ed.) Instructional leadership and leadership for learning in schools: Understanding theories of leading (pp. 77-104). Heidelberg, Germany: Palgrave Macmillan.

Gurr, D. (2020). Australia: The Australian education system. In H. Ärlestig \& O. Johansson (Eds) Educational authorities and the schools - organization and impact in 20 states (pp. 311-331). Dordrecht, Netherlands: Springer.

Gurr, D., \& Drysdale, L. (2016). Successful and effective school leadership: Insights from Australasia. In P. Pashiardis \& O. Johansson (Eds.), Successful school leadership: International perspectives (pp. 139-154). Bloomsbury.

Gurr, D., \& Drysdale, L. (2018). Leading high need schools: Findings from the international school leadership development network. International Studies in Educational Administration, 46(1), 147-156.

Gurr, D., \& Drysdale, L. (2019). Improving schools in Victoria, Australia: System, region and school perspectives. In H. Shaked, C. Schechter, \& A. Daly (Eds.), Leading holistically: How states, districts, and schools improve systemically (pp. 217-235). Routledge.

Gurr, D., Drysdale, L., Longmuir, F., \& McCrohan, K. (2018). Leading the improvement of schools in challenging circumstances. International Studies in Educational Administration, 46(1), 22-44.

Gurr, D., Drysdale, L., Longmuir, F., \& McCrohan, K. (2019). Successful school leadership that is culturally sensitive but not context constrained. In E. Murakami, D. Gurr, \& R. Notman (Eds.), Educational leadership, culture, and success in high-need schools (pp. 25-44). Information Age Publishing.

Gurr, D., Drysdale, L., \& Walkley, D. (2012). School-parent relations in Victorian schools. Journal of School Public Relations, 33(3), 172-198.

Harris, A. (Ed.). (2009). Distributed leadership: Different perspectives. Springer.

Hattie, J. (2003). Teachers make a difference: What is the research evidence? Paper presented at the Building Teacher Quality: What does the research tell us?, ACER Research Conference, Octover, Melbourne, Australia.

Hattie, J. (2009). Visible learning: A synthesis of over 800 Meta analyses relating to achievement. Routledge.

Hattie, J. (2012). Visible learning for teachers: Maximizing impact on learning. Routledge.

Hattie, J. (2015). What works best in education: The politics of collaborative expertise. Pearson.

Hattie, J. (2016). Shifting away from distractions to improve Australia's schools: Time for a reboot (Monograph, 54). Australian Council for Educational Leaders.

Heifetz, R. A., Grashow, A., \& Linsky, M. (2009). The practice of adaptive leadership. Harvard Business School Press.

Heifetz, R. A., \& Linsky, M. (2002). Leadership on the line: Staying alive through the dangers of leading. Boston, MA: Harvard Business School Press.

Huerta Villalobos, M. (2013). The role of the critical friend in leadership and school improvement. Master of Education thesis, The University of Melbourne. 
Kameniar, B., McLean Davies, L., Kinsman, J., Reid, C., Tyler, D., \& Acquaro, D. (2017). Clinical praxis exams: Linking academic study with professional practice knowledge. In M. A. Peters, B. Cowie, \& I. Menter (Eds.), A companion to research in teacher education (pp. 53-67). Springer.

Kotter, J., \& Rathgeber, H. (2006). Our Iceberg is melting. St Martin's Press.

Kriewaldt, J., McLean Davies, L., Rice, S., Rickards, F., \& Acquaro, D. (2017). Clinical practice in education: Towards a conceptual framework. In M. A. Peters, B. Cowie, \& I. Menter (Eds.), A companion to research in teacher education (pp. 153-166). Springer.

Leithwood, K., Harris, A., \& Strauss. (2010). Leading school turnaround. Jossey-Bass.

Leithwood, K., \& Riehl, C. (2005). What we know about successful school leadership. In W. Firestone \& C. Riehl (Eds.), A new agenda: Directions for research on educational leadership (pp. 22-47). Teachers College Press.

Lewis, M. (2006). It's a different place now: Teacher leadership and pedagogical change at Newlyn Public School. Leading and Managing, 12(1), 107-121.

Lewis, M., \& Andrews, D. (2007). The dance of influence: Professional relationships evolve as teachers and administrators engage in whole school renewal. Leading and Managing, 13(1), 91-107.

Lewis, R. (2008). The developmental management approach to classroom behaviour. Australian Council for Educational Research.

Major, G. (2018). A centre for continuous learning, Scoresby Secondary College. Scoresby Secondary College.

Marzano, R. J. (2003). What works in schools: Translating research into action. ASCD.

McCrohan, K. M. (2021). Practices and characteristics of principals in low educational advantage, improving Victorian secondary schools; contextually aware leadership. Doctor of Education Thesis, The University of Melbourne.

McLean Davies, L., Anderson, M., Deans, J., Dinham, S., Griffin, P., Kameniar, B., Page, J., Reid, C., Rickards, F., Tayler, C., \& Tyler, D. (2013). Masterly preparation: Embedding clinical practice in a graduate pre-service teacher education programme. Journal of Education for Teaching: International Research and Pedagogy, 39(1), 93-106.

Quality Indicators for Learning and Teaching. (2018). Graduate employment. [Online]. Available at: https://www.qilt.edu.au/about-this-site/graduate-employment. Accessed 13 Apr 2018.

Sahlberg, P. (2012). The most wanted: Teachers and teacher education in Finland. In L. DarlingHammond \& A. Lieberman (Eds.), Teacher education around the world: Changing policies and practices (pp. 1-21). Routledge.

Savage, G. C. (2017). Improving national policy processes in Australian schooling. In T. Bentley, \& G. C. Savage (Eds) Educational Australia: Challenges for the decade ahead (pp. 348-366). Carlton, Victoria: Melbourne University Press.

Scoresby Secondary College. (2018a). Pre-review Self-evaluation Report Strategic Plan 2015-2018 19/4/2018. Scoresby Secondary College.

Scoresby Secondary College. (2018b). 2018 annual report to the school community. Victorian Department of Education and Training.

Scott, C., Kleinhenz, E., Weldon, P., Reid, K., \& Dinham, S. (2010). Master of teaching MGSE: Evaluation report. Australian Council for Educational Research.

Swaffield, S. (2004). Critical friends: Supporting leadership, improving learning. Improving Schools, 7(3), 267-278.

Swaffield, S., \& MacBeath, J. (2005). School self-evaluation and the role of a critical friend. Cambridge Journal of Education, 35(2), 239-252.

Teacher Education Ministerial Advisory Group (2014a, April). Issues Paper, Department of Education and Training, Canberra, https://docs.education.gov.au/documents/ teacher-education-ministerial-advisory-group-issues-paper

Teacher Education Ministerial Advisory Group (2014b, December). Action now: Classroom Ready Teachers, Department of Education and Training, Canberra, https://docs.education.gov. au/system/files/doc/other/action_now_classroom_ready_teachers_accessible.pdf 
Timperley, H. (2010). Using evidence in the classroom for professional learning. Paper presented to the Ontario Research Symposium.

Wildy, H., \& Faulkner, J. (2008). Whole school improvement Australian-style: What do IDEAS and RAISe offer? Leading and Managing, 14(2), 83-96.

Zbar, V., Kimber, R., \& Marshall, G. (2009). Schools that achieve extraordinary success: How some disadvantaged Victorian schools 'punch over their weight (Occasional Paper 109). Incorporated Association of Registered Teachers of Victoria.

Zbar, V. (2013). Generating whole-school improvement: The stages of sustained success (Occasional Paper 132). Incorporated Association of Registered Teachers of Victoria.

Open Access This chapter is licensed under the terms of the Creative Commons Attribution 4.0 International License (http://creativecommons.org/licenses/by/4.0/), which permits use, sharing, adaptation, distribution and reproduction in any medium or format, as long as you give appropriate credit to the original author(s) and the source, provide a link to the Creative Commons license and indicate if changes were made.

The images or other third party material in this chapter are included in the chapter's Creative Commons license, unless indicated otherwise in a credit line to the material. If material is not included in the chapter's Creative Commons license and your intended use is not permitted by statutory regulation or exceeds the permitted use, you will need to obtain permission directly from the copyright holder.

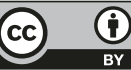

